\title{
Synthesis and Characterization of Polypyrrole (PPy) Thin Films
}

\author{
Manik A. Chougule ${ }^{a}$, Shailesh G. Pawar ${ }^{a}$, Prasad R. Godse ${ }^{a}$, Ramesh N. Mulik ${ }^{a}$, Shashwati Sen ${ }^{b}$, \\ Vikas B. Patil ${ }^{\mathrm{a}}$ *
}

${ }^{\mathrm{a}}$ Materials Research Laboratory, School of Physical Sciences, Solapur University, Solapur, India; ${ }^{\mathrm{b}}$ Crystal Technology Section, Bhabha Atomic Research Centre, Mumbai, India.

Email: drvbpatil@gmail.com

Received December $29^{\text {th }}, 2010$; revised January $12^{\text {th }}, 2011$; accepted January $15^{\text {th }}, 2011$.

\begin{abstract}
Polypyrrole (PPy) was synthesized by chemical oxidative polymerization technique using monomer pyrrole and ammonium persulphate as an oxidant in a ratio of 1:1. Thin films of polypyrrole were prepared by dissolving polypyrrole in $m$-cresol and cast using spin coating technique on glass substrates. Thin films of polypyrrole were characterized by $X$ ray diffraction (XRD), Scanning electron microscopy (SEM), Fourier transform infra red spectroscopy (FTIR), UV visible spectroscopy and electrical resistivity by four probe method. The XRD spectra showed that the polypyrrole is amorphous in nature. SEM studies revealed a uniform granular structure of PPy. The FTIR spectra shows that the presence of all characteristics absorption peaks of polypyrrole that is, $890 \mathrm{~cm}^{-1}(=C-H$ out-of-plane vibration), 1040 $\mathrm{cm}^{-1}$ (=C-H in-plane vibration), $1170 \mathrm{~cm}^{-1}$ ( $N-C$ stretch bending) and $1410 \mathrm{~cm}^{-1}$ (pyrrole ring vibration). UV visible study shows PPy films exhibit absorption peak at $446 \mathrm{~nm}(2.77 \mathrm{eV})$. Room temperature electrical resistivity of PPy is in the critical regime of the metal -to-insulator (M-I) transition.
\end{abstract}

Keywords: Polypyrrole, Chemical Polymerization, XRD, SEM, FTIR

\section{Introduction}

In recent years, intrinsic conducting polymers with conjugated double bonds have been attracted much attention as advanced materials. Among those conducting polymers, polypyrrole (PPy) is especially promising for commercial applications because of its good environmental stability, facile synthesis and higher conductivity than many other conducting polymers. PPy can often be used as biosensors [1,2], gas sensors [3,4], wires [5], microactuators [6], antielectrostatic coatings [7], solid electrolytic capacitor [8,9], electrochromic windows and displays, and packaging, polymeric batteries, electronic devices and functional membranes, etc. [10-12]. PPy coatings have an excellent thermal stability and are good candidate for use in carbon composites [13]. Furthermore, the electrochemical process parameters affecting the properties of the PPy coatings are also investigated [14]. PPy can be easily prepared by either an oxidatively chemical or electrochemical polymerization of pyrrole. However synthetically conductive PPy is insoluble and infusible which restricts its processing and applications in other fields. The problem has been extensively investi- gated and new application fields have also been explored in the past several years. For example, PPy-based polymers can be used to load and release drugs and biomolecules [15]. PPy-based polymer blends can protect the corrosion of metals [16].

In the present investigations attempts were made to report on our observation of structure morphology, electrical and optical properties of polypyrrole thin films using the spin coating technique.

\section{Experimental}

Polypyrrole (PPy) was synthesized by chemical oxidative polymerization technique using monomer pyrrole. Analytical grade ammonium per-sulphate APS, (Sd fine) was used as oxidizing agent. The chemical polymerization was carried out in a beaker by mixing $0.1 \mathrm{M}$ aqueous solution of pyrrole and $0.1 \mathrm{M}$ of APS in 1:1 ratio by volume. The polymerization was carried out for a period of three hours. After termination of polymerization process, the precipitate obtained was filtered. The product was washed successively by methanol followed by distilled water. The films of polypyrrole were deposited 
using spin coating method on pre cleaned glass substrate (size $10 \mathrm{~mm} \times 10 \mathrm{~mm}$ ). X-ray diffraction (XRD) studies were carried out using a Philips powder X-ray diffractometer (Model: PW1710). The XRD patterns were recorded in the $2 \theta$ range of $20-80^{\circ}$ with step width $0.02^{\circ}$ and step time $1.25 \mathrm{sec}$ using $\mathrm{CuK} \alpha$ radiation $(\lambda=1.5406$ $\AA ̊$ ). The morphology of the polypyrrole films was examined using Scanning Electron Microscope (SEM) (JEOL JSM 6360) using acceleration voltage of $25 \mathrm{kV}$. For this purpose thin layer of gold (50 ̊́) was deposited on the film using physical vapour deposition. Chemical structure of thin film was examined by FTIR technique (Model: Perkin Elmer 100) using uncoated glass as reference. UV-Vis spectra of the samples, which were dispersed in de-ionized water under ultrasonic action, were recorded on a Simandzu-100 UV-Vis spectrophotometer. For resistance measurement, two gold electrodes, separated by $1 \mathrm{~mm}$, were deposited on polypyrrole film and silver wires were attached using silver paint. The resistance was measured using four probe method.

\section{Results and Discussion}

\subsection{FTIR Analysis}

Figure 1 shows the FTIR spectra of PPy powder. The peaks at $811 \mathrm{~cm}^{-1}, 920 \mathrm{~cm}^{-1}$ are attributed to $\mathrm{C}-\mathrm{H}$ wagging $[17,18]$. The characteristic peaks at $1558.4 \mathrm{~cm}^{-1}$ and $1487 \mathrm{~cm}^{-1}$ correspond to the $\mathrm{C}=\mathrm{C}$ stretching, whereas peaks at $1685.7 \mathrm{~cm}^{-1}$ and $1315.4 \mathrm{~cm}^{-1}$ represent to respectively, $\mathrm{C}=\mathrm{N}$ and $\mathrm{C}-\mathrm{N}$ bonds [19]. The occurrence of small peaks at $3522 \mathrm{~cm}^{-1}$ is assigned to presence of $\mathrm{N}-\mathrm{H}$ stretching vibrations. The peaks observed in the present work match well with the ones available in the literature $[18,19]$ confirming the formation of Polypyrrole.

\subsection{XRD Analysis}

$\mathrm{X}$-ray diffraction studies show that the PPy powder is

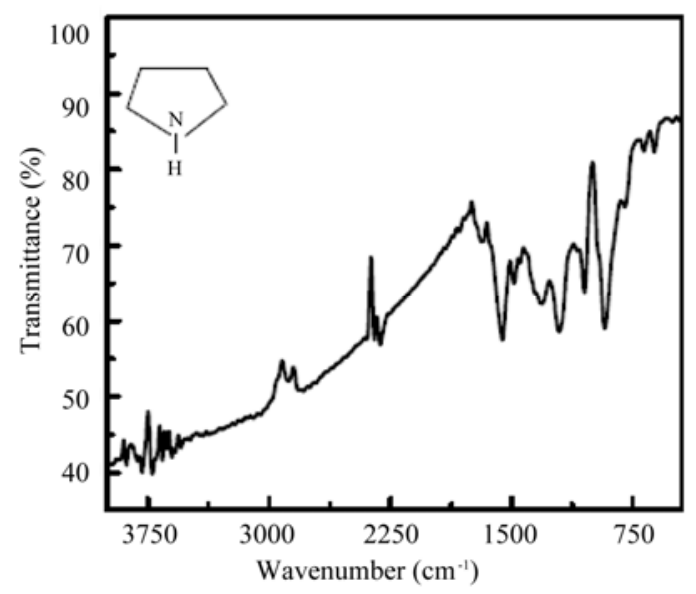

Figure 1. FTIR spectra of Polypyrrole film. Inset shows structure of pyrrole monomer.

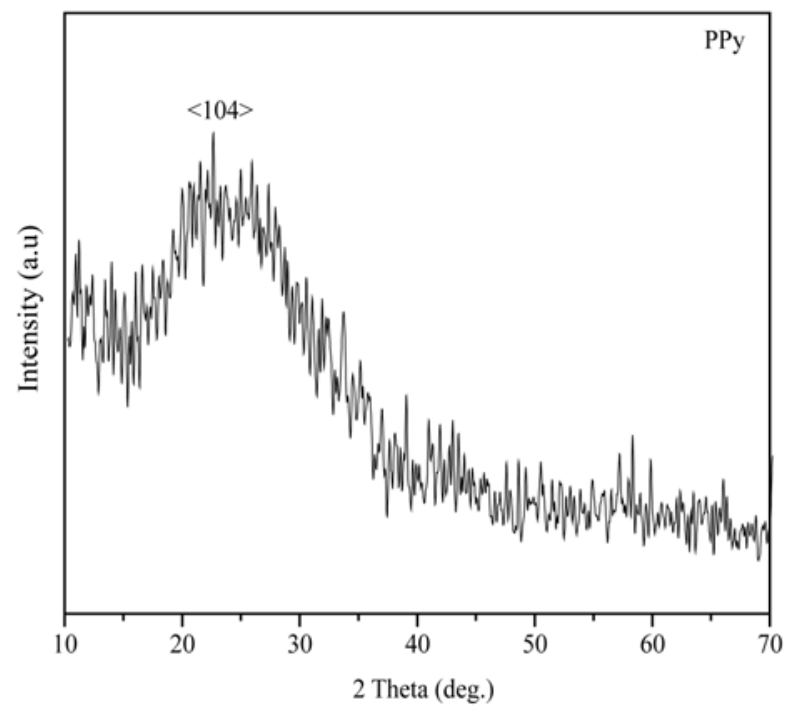

Figure 2. X-ray diffraction of PPy.

amorphous in nature, as shown in Figure 2. In Figure 2. broad peak was observed at about $2 \theta=24^{\circ}$. The broadpeak is characteristic of amorphous PPy [20] and are due to the scattering from PPy chains at the interplanar spacing [21]. The average chain separation can be calculated from these maxima using the relation [22-25].

$$
\mathrm{S}=5 \lambda / 8 \sin \theta
$$

Where $S$ is the polymer chain separation, $\lambda$ is the $\mathrm{X}$-ray wavelength and $\theta$ is the diffraction angle at the maximum intensity of the amorphous halo. The average chain separation $(R)$ was found to be $4.38 \AA$ for PPy.

The average crystallite size from a sharp peak at $24^{\circ}$ for PPy is estimated by using the Scherrer's formula [26].

$$
D=K \lambda / \beta \cos \theta
$$

Where $D$ is the crystallite size, $K$ is the shape factor, which can be assigned a value of 0.89 if the shape is unknown, $\theta$ is the diffraction angle at maximum peak intensity, and $\beta$ is the full width at half maximum of diffraction angle in radians. When applied to the sharp peaks, Equation (2) leads to the average crystallite size of about $56 \mathrm{~nm}$ for PPy powder.

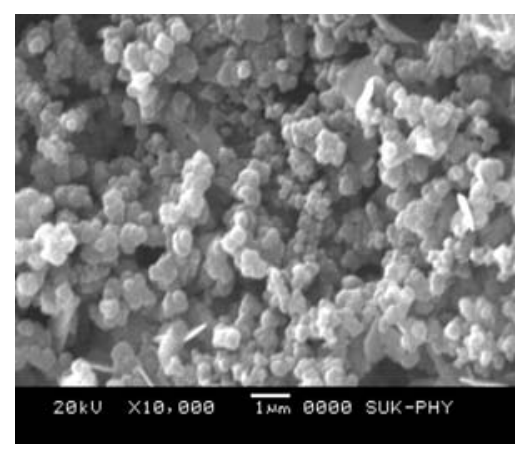

Figure 3. Microstructure of a polypyrrole thin film. 


\subsection{SEM Analysis}

The microstructure of a polypyrrole thin film is shown in Figure 3. The film has a uniform granular morphology and the average grain size is $\sim 0.7 \mu \mathrm{m}$.

\subsection{UV-Vis Analysis}

Figure 4 shows UV-Vis spectra of PPy film. PPy films exhibit absorption peak at $446 \mathrm{~nm}(2.77 \mathrm{eV})$ which are in agreement with literature values [27,28].

\subsection{Electrical Studies}

Figure 5 shows the variation of electrical resistance as a function of temperature of pure PPy. In this case it was observed that as temperature increases the electrical resistance decreases and hence conductivity increases. This suggests that the thermally activated behavior of conductivity has been confirmed. The decrease in resistance is due to the increase of efficiency of charge transfer in PPy

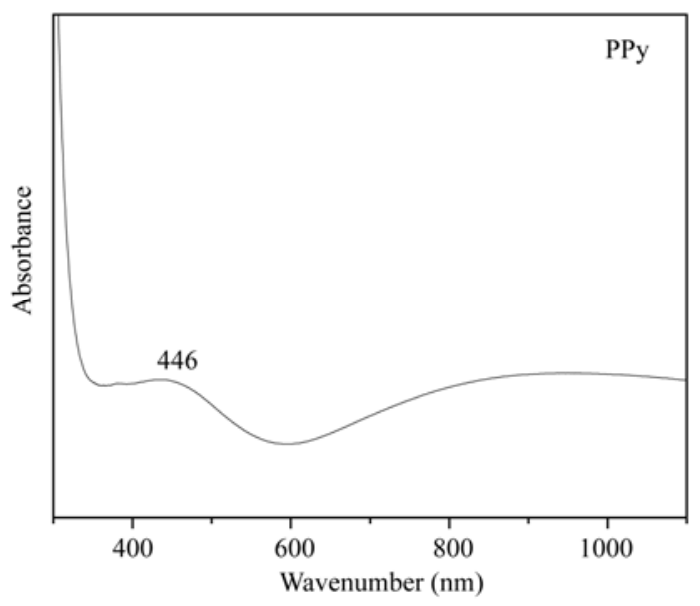

Figure 4. UV-Vis spectra of PPy film.

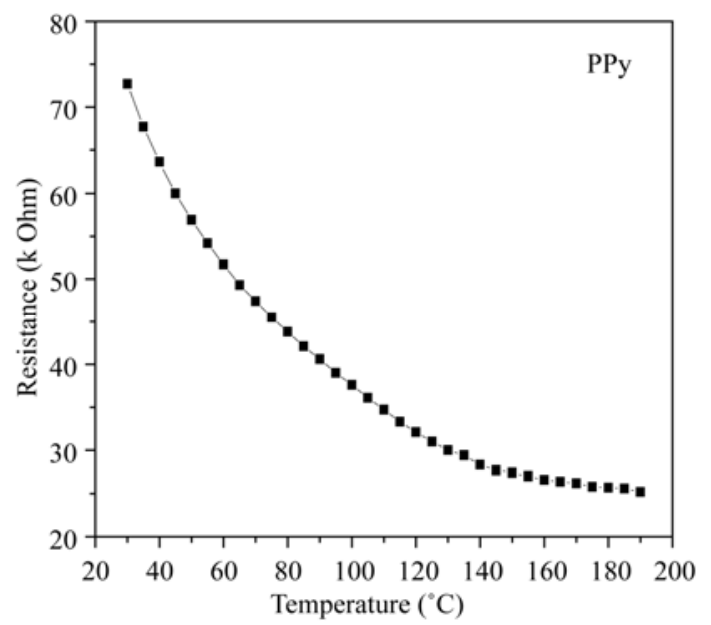

Figure 5. Variation of electrical resistance as a function of temperature of pure PPy. with increase in temperature [29-30]. It is also suggested that the thermal curling affects the chain alignment of the polymer, which leads to the increase of conjugation length and which in turn brings about the decrease in resistance. Also, there will be molecular rearrangement on heating, which make the molecules favorable for electron delocalization [31]. The temperature dependence of the conductivity for conducting polymers is expressed by a variable range hopping (VRH) model proposed by Mott [32]. According to this model the behavior of electronic conduction in disordered and non-metallic materials is controlled by the thermally assisted hopping of electrons between localized states near randomly distributed traps and the resistance is given by,

$$
\begin{aligned}
& R(T) \alpha \exp \left[-T_{0} / T^{1 /(n-1)}\right] \\
& k T_{0}=d \alpha^{3} / \rho_{0}
\end{aligned}
$$

where $\alpha$ is the coefficient of exponential decay of the localized states, $\rho_{0}$ is the density of states at the Fermi level, $k$ is Boltzmann's constant, $T_{0}$ is absolute temperature, $R(T)$ is resistance at room temperature, $n$ is number of electrons and $d$ is a dimensional constant. However, many models have predicted as $R=T^{-1 / 2}$.

\section{Conclusions}

The polypyrrole synthesized using chemical polymerization process. The films had a uniform granular morphology. The structure of the films is confirmed by FTIR and XRD techniques. UV-Vis studies showed that the PPy films exhibit absorption peak at $446 \mathrm{~nm}(2.77 \mathrm{eV})$. The PPy shows a thermally activated behavior of conductivity.

\section{Acknowledgements}

Authors (VBP) are grateful to DAE-BRNS, for financial support through the scheme no.2010/37P/45/BRNS/ 1442.

\section{REFERENCES}

[1] J. C. Vidal, E. Garcia and J. R. Castillo, "In situ Preparation of a Cholesterol Biosensor: Entrapment of Cholesterol Oxidase in an Overoxidized Polypyrrole Film Electrodeposited in a Flow System: Determination of Total Cholesterol in Serum," Analytica Chimica Acta, Vol. 385, No. 1-3, 1999, pp. 213-222. doi:10.1016/S0003-2670(98)00838-1

[2] T. E. Campbell, A. J. Hodgson and G. G. Wallace, "Incorporation of Erythrocytes into Polypyrrole to Form the Basis of a Biosensor to Screen for Rhesus (D) Blood Groups and Rhesus (D) Antibodies," Electroanalysis, Vol. 11, No. 4, 1999, pp. 215-222. 
doi:10.1002/(SICI)1521-4109(199904)11:4<215::AID-E LAN215>3.0.CO;2-\#

[3] D. Kincal, A. Kamer, A. D. Child and J. R. Reynold, "Conductivity Switching in Polypyrrole-Coated Textile Fabrics as Gas Sensors," Synthetic Metals, 92, 1998, pp. 53-55

doi:10.1016/S0379-6779(98)80022-2

[4] N. T. Kemp, G. U. Flanagan, A. B. Kaiser, H. J. Trodahl, B. Chapman, A. C. Partridge and R. G. Buckley, "Temperature-Dependent Conductivity of Conducting Polymers Exposed to Gases," Synthetic Metals, Vol. 101, No. 1-3, 1999, pp. 434-435.

doi:10.1016/S0379-6779(98)01118-7

[5] C. Jérôme, D. Labaye, I. Bodart and R. Jérôme, "Electrosynthesis of Polyacrylic/Polypyrrole Composites: Formation of Polypyrrole Wires," Synthetic Metals, Vol. 101, No. 1-3, 1999, pp. 3-4. doi:10.1016/S0379-6779(98)00524-4

[6] E. Smela, "Microfabrication of PPy Microactuators and Other Conjugated Polymer Devices," Journal of Micromechanics and Microengineering, Vol. 9, No. 1, 1999, pp. $1-18$.

doi:10.1088/0960-1317/9/1/001

[7] S. C. Yang, H. Liu, R. L. Clark, PCT Int. Application, WO 99 22, 380 (Cl.H01 B1/00).

[8] T. Takamatsu, Y. Taketani, Jpn. Kokai. Tokyo Koho JP11 121, 279 [99 121,279]

[9] Y Kojima, H. Kamikawa, T. Takamatsu, Jpn. Kokai. Tokyo Koho JP11 121, $280[99$ 121,280].

[10] T. A. Skotheim, "Handbook of Conducting Polymers," Marcel Dekker, New York, 1986.

[11] T. A. Skotheim, R. Elsenbaumer and J. Reynolds, "Hand-Book of Conducting Polymers," Marcel Dekker, New York, 1998

[12] G. G. Wallace, G. Spinks and P. R. Teasdale, "Conductive Electroactive Polymers," Technomic, New York, 1997.

[13] J. O. Iroh and C. Williams, "Formation of Thermally Stable Polypyrrole-Naphthalene/Benzene Sulfonate-Carbon Fiber Composites by an Electrochemical Process," Synthetic Metals, Vol. 99, No. 1, 1999, pp. 1-8. doi:10.1016/S0379-6779(98)00160-X

[14] W. Su and J. O. Iroh, "Effects of Electrochemical Process Parameters on the Synthesis and Properties of Polypyrrole Coatings on Steel," Synthetic Metals, Vol. 95, No. 3, 1998, pp. 159-167. doi:10.1016/S0379-6779(97)04112-X

[15] J. R. Reynolds, H. Ly, F. Selampinar and P. J. Kinlen, "Controlled Drug and Biomolecule Release from Electroactive Host Polymer Systems," Polymer Preprints, Vol. 40, No. 1, 1999, p. 307.

[16] W. K. Lu and R. A. Elsenbaumer, "The Corrosion Protection of Metal by Conductive Polymers II-Pitting Corrosion," Annual Technical Conference-Society of Plastics Engineers, Vol. 56, No. 2, 1998, pp. 1276-1281.
[17] H. J. Kharat, K. P. Kakade, P. A. Savale, K. Dutta, P. Ghosh and M. D. Shirsat, "Synthesis of Polypyrrole Films for the Development of Ammonia Sensor," Polymers for Advanced Technologies, Vol. 18, No. 5,2007, pp. $397-$ 402.

doi:10.1002/pat.903

[18] B. Tian and G. Zerbi, "Lattice-Dynamics and VibrationalSpectra of Polypyrrole," Journal of Chemical Physics, Vol. 92, No. 6, 2009, pp. 3886-3891. doi:10.1063/1.457794

[19] K. Arora, A. Chaubey, R. Singhal, R. P. Singh, M. K. Pandey, S. B. Samanta., B. D. Malhotra and S. Chand, "Application of Electrochemically Prepared PolypyrrolePolyvinyl Sulphonate Films to DNA Biosensor," Biosensors and Bioelectronics, Vol. 21, No. 9, 2006, 1777 1783. doi:10.1016/j.bios.2005.09.002

[20] R. E. Partch, S. G. Gangoli, E. Matijevic, W. Cai and S. Arajs, "Conducting Polymer Composites I: Surface-Induced Polymerization of Pyrrole on Iron(III) and Cerium (IV) Oxide Particles," Journal of Colloid and Interface Science, Vol. 144, No. 1, 1991, pp. 27-35. doi:10.1016/0021-9797(91)90234-Y

[21] J. Y. Ouyang and Y. F. Li, "Great Improvement of Polypyrrole Films Prepared Electrochemically from Aqueous Solutions by Adding Nonaphenol Polyethyleneoxy (10) Ether," Polymer, Vol. 38, No. 15, 1997, pp. 3997-3999. doi:10.1016/S0032-3861(97)00087-6

[22] L. E. Alexander, "X-ray Diffraction Methods in Polymer Science," John Wiley, New York, 1969.

[23] K. Cheah, M. Forsyth and V.-T. Truong, "An XRD/XPS Approach to Structural Change in Conducting PPy," Synthetic Metals, Vol. 101, No. 1-3, 1999, p. 19. doi:10.1016/S0379-6779(98)00790-5

[24] P. Lemon and J. Haigh, "The Evolution of Nodular Polypyrrole Morphology during Aqueous Electrolytic Deposition: Influence of Electrolyte Gas Discharge," Materials Research Bulletin, Vol. 34, No. 5, 1999, pp. 665-672. doi:10.1016/S0025-5408(99)00069-0

[25] K. Cheah, M. Forsyth and V.-T. Truong, "Ordering and Stability in Conducting Polypyrrole," Synthetic Metals, Vol. 94, No. 2,1998, pp. 215-219. doi:10.1016/S0379-6779(98)00006-X

[26] B. D. Cullity, "Elements of X-Ray Diffraction," Addison-Wesley Publishing Company Inc., London, 1978.

[27] Z. L. Wang, X. Y. Kong, Y. Ding, P. Gao, W. L. Hughes, R. Yang and Y. Zhang, "Semiconducting and Piezoelectric Oxide Nanostructures Induced by Polar Surfaces," Advanced Functional Materials, Vol. 14, No. 10, 2004, pp. $943-956$. doi:10.1002/adfm. 200400180

[28] H. Shiigi, M. Kishimoto, H. Yakabe, B. Deore and T. Nagaoka, "Highly Selective Molecularly Imprinted Overoxidized Polypyrrole Colloids: One-Step Preparation Technique," Analytical Sciences, Vol. 18, No. 1, 2002, pp. 41-44. doi:10.2116/analsci.18.41 
[29] M. Leclerc, G. D’Aparno and G. Zotti, "Structure-Property Relationships in Polyaniline Derivatives," Synthetic Metals, Vol. 55, No. 2-6, 1993, pp. 1527-1532. doi:10.1016/0379-6779(93)90279-6

[30] F. Zuo, M. Angelopoulos, A. G. MacDiarmid and A. J. Epstein, "Transport Studies of Protonated Emeraldine Polymer: A Granular Polymeric Metal System," Physical Review B: Condensed Matter and Materials Physics, Vol. 36, No. 5, 1987, pp. 3475-3478.
doi:10.1103/PhysRevB.36.3475

[31] A. Kobayashi, H. Ishikawa, K. Amano, M. Satoh and E. Hasegawa, "Electrical Conductivity of Annealed Polyaniline," Journal of Applied Physics, Vol. 74, No. 1, 1993, pp. 296-299. doi:10.1063/1.354106

[32] N. F. Mott and E. Davis, "Electronic Processes in Noncrystalline Materials," Clarendon Press, Oxford, 1979. 